\title{
Professionalism and leadership in medical education: how do they differ and how are they related?
}

\author{
Louise Jessica Hardy, Hilary Neve
}

Faculty of Medicine and Dentistry, University of Plymouth, Plymouth, UK

\section{Correspondence to}

Louise Jessica Hardy, Faculty of Medicine \& Dentistry, University of Plymouth, Plymouth PL6 8BU, UK;

louise.hardy@plymouth.ac.uk

Received 2 September 2019 Accepted 16 September 2019

Check for updates

(c) Author(s) (or their employer(s)) 2019. No commercial re-use. See rights and permissions. Published by BMJ.

To cite: Hardy LJ, Neve $\mathrm{H}$. BMJ Leader 2019;3:67-68.
It is widely accepted that both professionalism and leadership are important in medicine and in recent years have been defined and mandated by the General Medical Council (GMC). ${ }^{1-3}$ Yet, the definitions of each are complex, vary between cultures and will almost certainly continue to be debated. Both are social constructs and there is undoubtedly a close association and significant overlap between the two. So how do we see the relationship between 'professionalism' and 'leadership'? Are they identical twins, sharing DNA which makes it impossible to differentiate between them in anything but name? Or siblings who share some characteristics but remain, at their heart, individuals pursuing separate identities, personalities and demanding semantic interpretations which are distinctly different?

Few would argue that professionalism and leadership share a value set which overlaps in many areas, explained clearly by reference to inarguable principles of sound behavioural qualities which might be characterised either as leadership or professionalism. ${ }^{4}$ To be an effective leader in health, you need to demonstrate high standards of professionalism in all your roles. The GMC defines excellence in professionalism through a range of descriptors and desired competencies. ${ }^{1}$ They include being able to work collaboratively in teams and with patients, giving and responding to feedback, dealing effectively with stress, challenge and uncertainty, prioritising time well, ensuring a good home-work balance, promoting patient safety, working ethically and managing your own learning and development. Leadership includes all of these, while shifting the focus beyond the direct delivery of high-quality patient care by individuals and teams. In a way leadership is about 'taking professionalism outwards'. Being an excellent leader involves seeing and acting on opportunities and influencing and bringing others with you to improve quality within the wider healthcare environment. Leadership requires individuals to understand healthcare and political systems and to build on their existing professionalism skills to be become effective in areas such as negotiation, facilitating change and project management. Many of these qualities appear in two frameworks which guide those who strive to deliver leadership education and development in the National Health Service (NHS). First, the Medical Leadership Competency Framework ${ }^{5}$ and second, the NHS Leadership Academy's more recent Healthcare Leadership Model. ${ }^{6}$

Understandings of professionalism have also extended beyond the individual to incorporate interpersonal, team and organisational elements as well as doctors' responsibilities to their communities and to society. ${ }^{7}$ In addition, professionalism is increasingly being viewed in terms of a developing professional identity-the beliefs and values that determine how individuals describe and view themselves as a medical student or doctor. ${ }^{8}$ Definitions of professionalism are influenced by cultural norms and differences and inevitably develop over time, as expectations of doctors, their learning and working contexts, technology and societal priorities also change.

In his contribution to the NHS's key framework for leadership, ${ }^{9}$ Professor Michael West points towards the need for compassionate leadership, citing four behaviours which could, arguably, define professionalism as much as leadership. They include attending to and understanding situations faced by both staff and patients, empathising with distress and helping to alleviate this distress. Moreover, there are evidence-based interventions which the leader can enact to encourage cultures of compassion, and these include the creation of clear and achievable objectives, exemplary people management and active support for effective teamworking and improvement. These interventions are the hallmarks of excellent leadership and go beyond the conceptual ideal of compassion and into the territory of active personal development.

Key questions, therefore, are 'how do I learn; what do I need to be able to demonstrate; and by when?' Not unreasonable in these times of portfolios, tests, ladders of competency, signoff, tick boxes and attainment. For medics, leadership grows best through a spiral learning approach, where leadership is acquired through experience, reflection and knowledge throughout their careers. Putting it another way, leadership development is never 'finished', can be situation dependent and is often (but not always) related to the medic's level of seniority in the NHS. At the basic end of the continuum (the start of the medical career, or even in medical school), it requires the individual to 'lead self' by, for example, running to time, staying on top of priorities in both life and work and perhaps even acquiring some basic management skills such as overseeing a quality improvement project, or a rota. As the leader takes on wisdom, experience and more complex roles, she/he will need to develop and integrate deeper leadership abilities, such as how to manage other people, systems knowledge, greater self-awareness, emotional intelligence, the ability to resolve multifaceted problems and a willingness to reflect on and adapt leadership practice in the light of feedback. Some will learn these skills and 
develop these capabilities more quickly than others, influenced perhaps by the opportunities presented and the level of personal interest. Skilled leaders will recognise the need to flex their approach in different situations in order to maximise the effect of their leadership. They will feel comfortable with the notion that the NHS environment is constantly changing and unpredictable, requires collaboration not control, listening not telling and that answers to questions are not always clean or definitive and may not be palatable to all. The newly recommended curriculum for developing leadership in medical undergraduates (FMLM 2018) recognises that young doctors in training require basic leadership in the early years of training (initially, perhaps, just an awareness of leadership), moving on towards understanding systems, organisations and deeper personal leadership as they progress through their careers. ${ }^{2}$ Royal Colleges will be building on this through inclusion of a suite of Professional and Generic Capabilities (which includes leadership) in all curricula, to be assessed throughout specialty training. The notion of 'shared' or 'collective' leadership, ${ }^{10}$ where leadership is distributed across the organisation with everyone taking responsibility for its success, offers opportunities for doctors at all stages of their career. A key element of leadership, particularly where shared, is 'followership'-the ability to actively and effectively support the leadership of others. ${ }^{11}$

Professionalism is similarly mandated by the GMC, and arguably we can describe professionalism on a continuum in the same way as with leadership. Becoming an effective self-regulated learner ${ }^{12}$ and reflecting on experience ${ }^{13}$ have both been identified as key to developing as a professional. The literature also emphasises the impact of positive role models, ${ }^{14}$ the influence of power and hierarchy on learners' professional development and the importance of being alert to the risks and benefits of the hidden curriculum. ${ }^{15}$ It seems likely that these are also key factors in leadership development. Alongside this, increasing awareness of equality and diversity issues, unconscious bias, the \#MeToo movement, the rise of social media and patients' use of the internet are influencing professionalism curricula, as are the issues of resilience, well-being and burnout. Research showing that gender and anxiety may increase burnout in the transition from student to doctor (while a strong professional and social identify may be protective ${ }^{16}$ ) highlights the inter-relatedness of these issues, as well as raising questions about the responsibilities of organisations, teams and their leaders in protecting and supporting the professional development of members.

So surely, when discussing the ability of an individual to conduct him/herself with confidence, integrity at work and to inspire trust in others-we are talking about both leadership and professionalism? On the other hand, there appear to be specific skills and values associated with professionalism which can and should be developed over time, with careful attention being paid to the development of the individual as he/she progresses through their career. The latter is certainly expected of leaders.

Few would argue that professionalism is a feature of medical life which should begin at the beginning (in medical school) and remain firmly at the heart of the individual throughout his/ her career. While recipients of care might reasonably expect their doctors to hold many of these qualities from the off, they would certainly expect them to be continually learning, developing and refining their professionalism as they progress (and thus, continuously improving). Meanwhile effective leadership includes creating a culture which values, motivates and supports people to become exceptional professionals, as well as engaging and empowering others to develop their own leadership qualities and abilities. In doing so, successful leaders will ensure that their organisation continues to deliver excellence and improve quality as it moves forward into the future.

It is hard, therefore, to tidily conclude this article in any agreeable fashion other than to note that there are distinct but key differences which point more favourably towards the earlier metaphor of close siblings. We leave you, therefore, with the contention that leadership requires and promotes professionalism but that professionalism may not, in and of itself, qualify you to lead. To lead effectively, you should actively attend to its development throughout your career. Professionalism will run throughout; the beating heart of your leadership, of your identity and of your reputation as an excellent doctor.

Twitter Louise Jessica Hardy @LouiseHardyOD and Hilary Neve @hilary_neve

Funding The authors have not declared a specific grant for this research from any funding agency in the public, commercial or not-for-profit sectors.

Competing interests None declared.

Patient consent for publication Not required.

Provenance and peer review Not commissioned; internally peer reviewed.

\section{REFERENCES}

1. GMC. Achieving good medical practice: guidance for medical students. London: General Medical Council, 2016.

2. GMC. Professional generic capabilities framework. London: General Medical Council, 2017.

3. GMC. Outcomes for graduates. London: General Medical Council, 2018.

4. McKimm J, O'Sullivan H. Doctor as professional and doctor as leaders: same attributes, attitudes and values? British Journal of Hospital Medicine 2011;72:463-6.

5. NHS Institute for Innovation and Improvement and the Academy of Medical Royal Colleges. Medical Leadership Competency Framework. 3rd. Coventry: NHS Institute for Innovation \& Improvement, 2010.

6. NHS Leadership Academy. The NHS healthcare leadership model, 2013. Available: https://www.leadershipacademy.nhs.uk/resources/healthcare-leadership-model/ [Accessed 9 May 2019].

7. Hodges BD, Ginsburg $S$, Cruess R, et al. Assessment of professionalism: recommendations from the Ottawa 2010 conference. Med Teach 2011:33:354-63.

8. Cruess RL, Cruess SR, Boudreau JD, et al. A schematic representation of the professional identity formation and socialization of medical students and residents: a guide for medical educators. Acad Med 2015;90:718-25.

9. NHS Improvement. Developing people improving care: evidence-based national framework to guide action on improvement skill-building, leadership development and talent management for people in NHS-funded roles, 2016. Available: https:// improvement.nhs.uk/resources/developing-people-improving-care/ [Accessed 22 May 2019].

10. West M, Ecker R, Steward K, et al. 'Developing Collective Leadership for health care', 2014. The King's Fund and Center for Creative Leadership. Available: https://www. kingsfund.org.uk/publications/developing-collective-leadership-health-care

11. Kelley RE. In praise of followers. Harvard Business Review Case Services, 1988: $142-8$.

12. van Houten-Schat MA, Berkhout JJ, van Dijk N, et al. Self-Regulated learning in the clinical context: a systematic review. Med Educ 2018:52:1008-15.

13. Mann K, Gordon J, MacLeod A. Reflection and reflective practice in health professions education: a systematic review. Adv Health Sci Educ Theory Pract 2009;14:595-621.

14. Passi V, Johnson $S$, Peile $E$, et al. Doctor role modelling in medical education: BEME guide No. 27. Med Teach 2013;35:e1422-36.

15. Neve $H_{1}$ Collett T. Empowering students with the hidden curriculum. Clin Teach 2018;15:494-9.

16. Monrouxe LV, Bullock A, Tseng H-M, et al. Association of professional identity, gender, team understanding, anxiety and workplace learning alignment with burnout in junior doctors: a longitudinal cohort study. BMJ Open 2017;7:e017942. 